\title{
Prader-Willi syndrome: A primer for clinicians
}

\author{
Mary Cataletto ${ }^{1 *}$, Moris Angulo', Gila Hertz ${ }^{2}$ and Barbara Whitman ${ }^{3}$
}

\begin{abstract}
The advent of sensitive genetic testing modalities for the diagnosis of Prader-Willi syndrome has helped to define not only the phenotypic features of the syndrome associated with the various genotypes but also to anticipate clinical and psychological problems that occur at each stage during the life span. With advances in hormone replacement therapy, particularly growth hormone children born in circumstances where therapy is available are expected to have an improved quality of life as compared to those born prior to growth hormone.

This manuscript was prepared as a primer for clinicians-to serve as a resource for those of you who care for children and adults with Prader-Willi syndrome on a daily basis in your practices. Appropriate and anticipatory interventions can make a difference.
\end{abstract}

\section{Introduction}

First described by Prader, Labhart and Willi in 1956 [1], this syndrome represents the most common genetic cause of obesity with an estimated incidence of 1:15,000 to $1: 25,000$ live births $[2,3]$. Reported prevalence rates vary among countries but both sexes appear to be equally affected. Prader-Willi syndrome (PWS) is the first human syndrome identified with genomic imprinting [4]. The original descriptions of this syndrome included short stature, hypotonia, hypogonadism and mental retardation [1]. As infants grow to age 2-4 years, failure to thrive related, at least in part, to poor muscle tone and poor suck are replaced by increased appetite and food intake resulting in obesity and its comorbidities. Early diagnosis and intervention to prevent obesity and the associated complications are critical.

\section{Genetic testing and genetic counseling}

Candidate genes for Prader-Willi syndrome have been located on the long arm of chromosome 15q11-q13. These genes are physiologically imprinted and silenced on the maternally inherited chromosome. PWS arises when the paternally derived genes are missing, defective or silenced. The frequencies of each are shown in Table 1.

High resolution chromosomal analysis (HRCA) is done along with the fluorescence in situ hybridization

\footnotetext{
* Correspondence: mcataletto@winthrop.org

'The Prader-Willi Syndrome Center at Winthrop University Hospital, 120

Mineola Blvd.-Suite 210, Mineola, N.Y. 11501, USA

Full list of author information is available at the end of the article
}

(FISH) to detect deletions and translocation of chromosome 15 [5]. Deletion has been divided in type I (TI) and II (TII) according to the size. Studies indicate that individuals with the TI ( 500 kb larger than TII) generally have more behavioral and psychological problems than individuals with the TII and UPD [6]. Negative FISH or karyotype analysis does not exclude the diagnosis and thus if done first should be followed by DNA methylation analysis. DNA methylation analysis is the only technique which can both confirm and reject the diagnosis of PWS, and therefore should typically be the investigation of choice. This is most commonly done using DNA methylation-specific techniques at the SNURF-SNRPN locus $[7,8]$. If DNA methylation analysis shows only a maternal pattern, then PWS is confirmed. Further methods may then be performed to determine the genetic subtype and allow appropriate genetic counseling. DNA methylation analysis has a sensitivity exceeding 99\%; however, it does not differentiate between deletion, UPD and imprinting defect. In order to distinguish a maternal UPD from an imprinting defect, further DNA polymorphism analysis should be performed on the proband and parents $[9,10]$.

Most cases of Prader-Willi syndrome occur sporadically. The overall recurrence risk is dependent on the type of molecular defect. In families where the proband has either maternal disomy or deletion, the recurrence risk is small (less than 1\%). Patients with an imprinting defect warrant further investigation in a specialized laboratory to determine whether an imprinting center deletion is present. Those families with a child with an 
Table 1 Frequency of genetic subtypes associated with PWS

\begin{tabular}{ll}
\hline Subtype & Frequency \\
\hline \hline Paternal deletion of chromosome 15q11-q13 (type I or II) & $75 \%$ \\
\hline Maternal uniparental disomy (UPD) & $24 \%$ \\
\hline Imprinting center defects (ID) & $1 \%$ \\
\hline Translocation & $<1 \%$ \\
\hline
\end{tabular}

imprinting center deletion have a recurrence risk of up to $50 \%$ if the father of the child is a carrier for the imprinting center deletion [11]. When a deletion is the result of a translocation or structural rearrangement involving chromosome 15, then the recurrence risk can be high. The actual risk in individual families depends upon the rearrangement which they carry. Overall, the risk of recurrence in the case of chromosomal translocations has been estimated up to $15 \%$.

In the future the methylation-specific multiplex ligation PCR amplification may be more widely used because it has the advantage of combining dosing and DNA methylation analysis in one assay, thus distinguishing different subtypes [12].

\section{Clinical Presentation}

Infants with Prader-Willi syndrome present with neonatal hypotonia, hypoplasia of the clitoris/labia minora in girls and small penis and undescended testis in boys. Their hypotonia is associated with poor suck and feeding, often resulting in failure to thrive. Mothers may report decreased fetal activity and infants are often found in the breech position at the time of delivery. Clinical features include increased neonatal head:chest circumference ratio, narrow bifrontal diameter, dolichocephaly, almond shaped eyes, downturned angles of the mouth with abundant and thick saliva, small hands and feet with straight borders of the ulnar side of the hands and inner side of the legs. The presence of some of these features associated with neonatal hypotonia should alert physicians for early diagnosis of PWS during infancy. These features may become more prominent by age 2-3 years (Figures 1 and 2). Excessive eating and obsession with food generally begins in the preschool age group and will lead to morbid obesity if not controlled.

As these individuals age, manifestations, such as obesity, short stature, hypogonadism, skin picking, learning disabilities, behavioral and psychiatric problems become more evident. Consensus criteria for the clinical diagnosis of PWS were first established in 1993 by Holm et al [13]. These criteria were used until the introduction of the highly sensitive genetic testing, described above. Currently, these criteria are used as a screening tool for determining the need for further PWS specific genetic

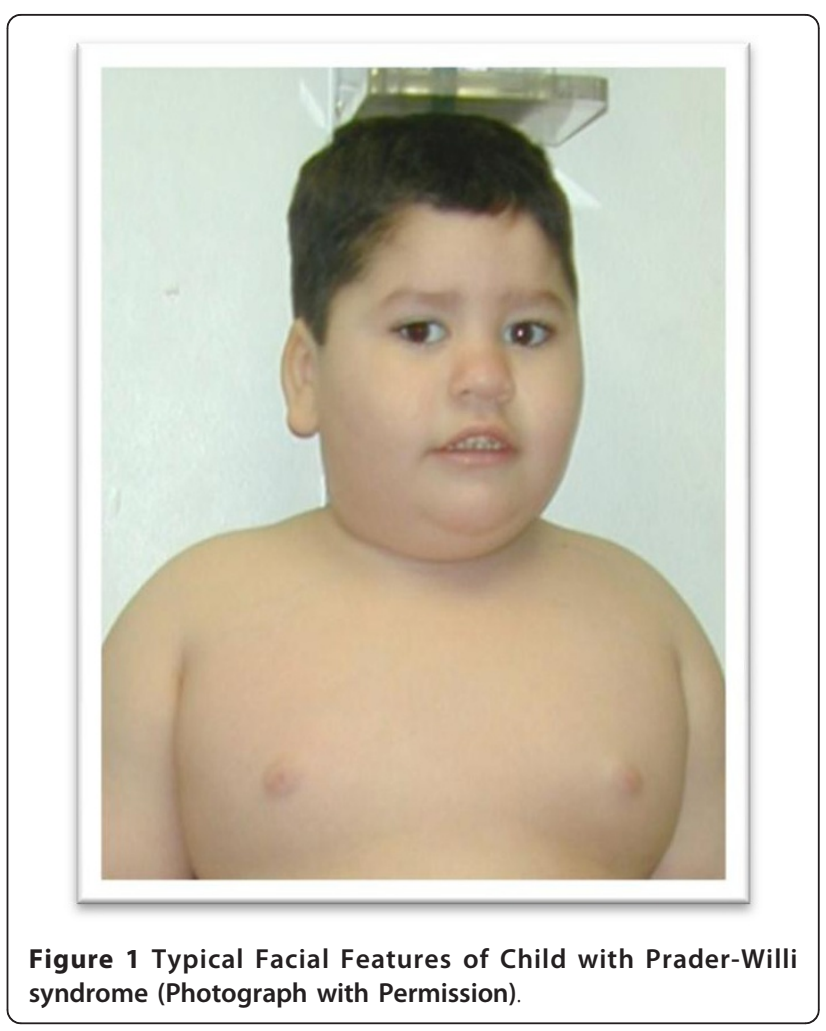

testing. In many infants poor cry and unexplained hypotonia may be the only clear clinical manifestations and indication for genetic testing.

As many as $16.7 \%$ of patients diagnosed with molecular testing do not meet these clinical diagnostic criteria, therefore a revised clinical criteria to help identify the appropriate patients for DNA testing was proposed in 2001 [14] and modified in 2008 [15]. See Table 2 for composite, including additional features suggested by authors.

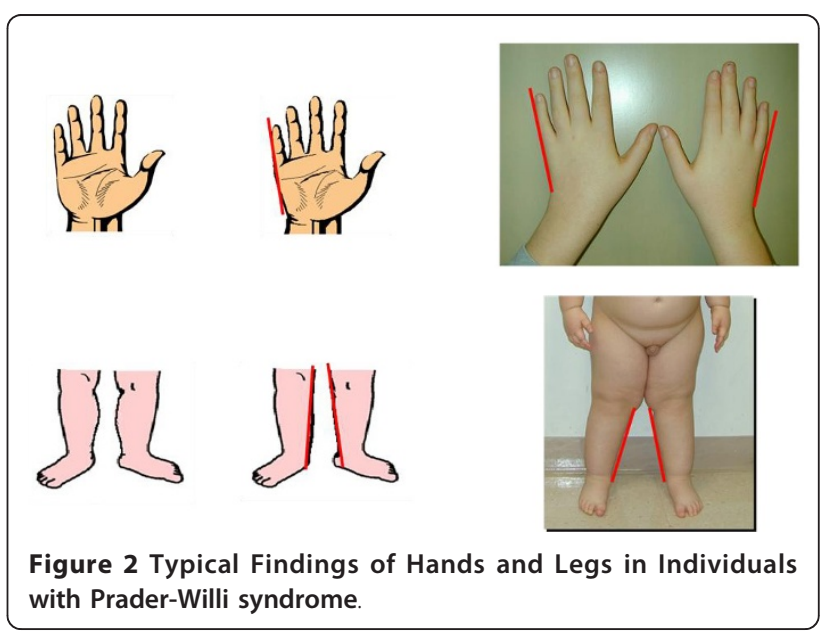


Table 2 Indications for DNA testing

\begin{tabular}{ll}
\hline Age at assessment & Features sufficient to prompt DNA testing \\
\hline Birth to 2 yr & Hypotonia with poor suck \\
2-6 yr & Hypotonia with a history of poor suck \\
& Global developmental delay \\
& Short stature and/or growth failure associated with accelerated weight gain \\
& Hypotonia with a history of poor suck (hypotonia often persists) \\
& Global developmental delay \\
& Excessive eating (hyperphagia, obsession with food) with central obesity if uncontrolled \\
& Short stature and/or decreased growth velocity* \\
& Cognitive impairment, usually mild mental retardation \\
13 yr through & Excessive eating (hyperphagia, obsession with food) with central obesity if uncontrolled \\
adulthood & Short stature and/or decreased growth velocity* \\
& Hypothalamic hypogonadism and/or typical behavior problems (including temper tantrums and obsessive-compulsive \\
& features) \\
\hline
\end{tabular}

*Features added by the authors

\section{Endocrine Issues Hypogonadism}

Hypothalamic and pituitary dysfunction is most commonly manifested as hypogonadism, obesity and short stature. Hypogonadism with genital hypoplasia (cryptorchidism, scrotal or clitoral hypoplasia) can be identified in the newborn period. Cryptorchidism is present up to $86 \%$ of boys from birth $[16,17]$ Undescended testes should be treated within the first year of life. There is evidence that early damage to the germ cells that produce sperm begins at this age. Scrotal hypoplasia and small penis however can make orchiopexy and circumcision difficult in infants with PWS. Repeat surgical interventions are frequently required, especially in those infants with underdeveloped scrotal sacs.

The most effective treatment for undescended testes is surgery. The Committee on Genetics, American Academy of Pediatrics however, recommends a therapeutic trial of human chorionic gonadotropin (hCG) for treatment of undescended testes before surgery, because avoidance of general anesthesia is desirable for infants with low muscle tone and potential for underlying respiratory compromise [18]. The precise mechanism of action in regards to testicular descent is unknown but benefits of a course of hCG may include increased scrotal size and partial normalization of phallus length, thereby improving surgical outcomes for undescended testes and facilitating later standing micturition.

Premature adrenarche (PA) is the precocious appearance of pubic and/or axillary hair and less commonly an apocrine odor, comedones, and acne without other signs of puberty or virilization. PA is usually seen before age 8 and 9 years, in girls and boys respectively. PA has been reported in $57 \%$ of children receiving GH therapy [19] but in general, pubertal development in PWS is characterized by normal adrenarche, pubertal arrest, and hypogonadism due to variable combinations of a unique primary gonadal defect and hypothalamic dysfunction $[20,21]$.

At some stage almost all subjects will require sex hormone replacement therapy. Mental retardation should not be a contraindication to allow normal pubertal development or preclude sex hormone replacement at any age in those affected individuals. Regardless of body weight, patients with PWS have increased body fat content. Those individuals with low body weight or significant low sex hormone levels during adolescence and adulthood should be considered for sex hormone treatment. There is no consensus as to the most appropriate regimen for sex hormone replacement therapy in PWS. Intramuscular testosterone is given every $3-4$ weeks. Testosterone gel preparations can be useful in selected cases, although precautions must be taken to avoid cross-contamination. Whatever preparation is preferred, the initial dose should be one third to one half of the normally recommended androgen dose to prevent the aggressive behavior occasionally seen in some individuals. In females with PWS, the use of gonadal hormone replacement should be considered if there is amenorrhea/oligomenorrhea or decreased bone mineral density (BMD) in the presence of reduced estradiol levels. Hypogonadism is a common but not necessarily universal finding in adults with PWS [16,17]. Sexual counseling and contraceptive treatment should be used as appropriate, especially in the presence of complete sexual maturation, including regular menses. There are a few case reports of pregnancy in females with PWS $[22,23]$. Their cognitive dysfunction, social and emotional immaturity and the risk of Angelman syndrome in offspring of PWS deletion mothers prompt us to advise against pregnancy. At present there are no reports of paternity in PWS. Estrogen and androgen 
status should be monitored yearly during adolescence and adulthood and BMD assessed as indicated by dualenergy $\mathrm{x}$-ray photon absorptiometry.

\section{Adrenal insufficiency}

When the pituitary begins to fail, there is generally a specific sequential failure of pituitary hormones, starting with growth hormone $(\mathrm{GH})$, continuing through luteinizing ( $\mathrm{LH})$ and follicle stimulating hormone (FSH) deficiency, and culminating in the loss of thyrotropin stimulating hormone (TSH) and adrenocorticotropic hormone (ACTH). Generally ACTH is the last to be affected. Hypothalamic dysfunction is characteristic of individuals with PWS, therefore the clinical manifestations of pituitary hormone deficiency are expected. Short stature and hypogonadism, as a result of GH and gonadotropin ( $\mathrm{LH}$ and FSH) deficiencies are seen in most individuals with this genetic syndrome. Under normal conditions the secretion of cortisol, the main adrenal glucocorticoid in humans is under the dominant control of pituitary ACTH. Clinical manifestations of adrenal insufficiency, however are uncommon in individuals with PWS.

The circadian peak serum cortisol usually occurs around 0800 hours. An extremely low basal serum cortisol at this time, below $100 \mathrm{nmol} /$ liter $(3.62 \mathrm{mcg} / \mathrm{dl})$, may be assumed to demonstrate true cortisol deficiency [24]. However, levels at other times have little diagnostic utility. For this reason, various dynamic tests including insulin tolerance test (ITT), ACTH stimulation and metyrapone test have been devised to assess whether the patient can provide a stress-induced rise in cortisol similar to a normal person. The insulin tolerance test evaluates the integrity of the entire hypothalamic-pituitary axis (HPA) by inducing symptomatic and biochemical hypoglycemia, with cortisol then measured over 120 minutes. Peak cortisol values greater than $550 \mathrm{nmol} / \mathrm{liter}$ $(19.75 \mathrm{mcg} / \mathrm{dl})$ is considered a normal response. Under supervision by a nurse or physician, the ITT $(0.15 \mathrm{U} / \mathrm{kg}$ administered intravenously (IV) is relatively safe [24]. The GH reserve can also be estimated with ITT.

Due to the relative inconvenience of the ITT, suggestions have been made to use a simpler and less invasive surrogate. The most widely performed is the short ACTH (Cortrosyn TM) stimulation test, where ACTH $0.25 \mathrm{mg}$ is injected IV or IM and serum cortisol is measure at 0,30 and 60 minutes. A peak cortisol is defined as normal if it is greater than $550 \mathrm{nmol} /$ liter $(19.75$ $\mathrm{mcg} / \mathrm{dl}$ ) at any of these time points.

In 2008 a study using the overnight metyrapone test reported a $60 \%$ prevalence of central adrenal insufficiency (CAI) in children with PWS [25]. Based on the high prevalence of CAI, the authors suggested treatment with hydrocortisone during acute illness in patients with
PWS unless CAI has recently been ruled out with a metyrapone test. ITT, as the gold standard dynamic test suggests that metyrapone test with an ACTH cut off of $33 \mathrm{pmol} / \mathrm{l}$ yields a high false positive rate. In our experience in the PWS center at Winthrop University Hospital, New York, we have not found any abnormal response to ITT or low cortisol levels during surgical stress of different natures. Three recent studies using a more sensitive stimulation and spontaneous acute stress in larger numbers of patients did not find high prevalence of central adrenal insufficiency in Prader-Willi syndrome [26-28]. Thus rather than common, CAI seems to be a rare event in children and adults with PWS, however, they should be evaluated and treated accordingly.

\section{Growth \& Growth hormone deficiency}

Length in newborns with PWS is normal but there is significant decrease in growth velocity after age 2-3 years with final adult height $\sim 2$ standard deviations (SD) below the mean for the normal population [29-31]. Only a small percentage of children with PWS are GH sufficient, thus provocative testing is not required in the face of reduced growth velocity.

Multiple studies have documented the benefits of GH therapy in individuals with PWS including, but not limited to, improvements in lean body mass, decreased body fat, increased bone mineral density, and normalization of adult height [19,32-37]. The benefits of starting GH treatment as early as age 2 years are well established, but there is increasing evidence of additional benefit to starting therapy between ages 6-12 months, particularly in terms of motor development, muscle, head circumference, and possibly cognition [35-38].

It should be stressed that GH therapy should be used in conjunction with appropriate nutritional intake and physical activity. GH treatment should not be viewed as a substitute for diet and exercise. Treatment should commence using standard dose guidelines $(0.18-0.3 \mathrm{mg} /$ $\mathrm{kg} /$ week), given as a daily subcutaneous injection with careful monitoring of clinical status at regular intervals. Careful history and assessment of nutritional status, scoliosis, respiratory and sleep abnormalities should be evaluated prior to and during GH therapy.

Recent studies indicate that adults with Prader-Willi syndrome may also benefit from GH replacement therapy, with improvements in body composition, bone mineral density, exercise capacity, quality of life and well-being [39-45]. Treatment doses are typically started at $0.2 \mathrm{mg} /$ day and increased by $0.2 \mathrm{mg}$ increments as necessary to maintain IGF-1 levels within the normal range for age and gender. At the present time, documentation of GH deficiency by provocative testing is required for adults with PWS to receive insurance 
authorization for GH treatment in the United States. These patients should be monitored with IGF-1, glucose, insulin, lipid profile, BMD and cardiac evaluation during GH treatment [46].

Central hypothyroidism as a result of hypothalamic dysfunction can also be seen in individuals with PWS. Periodic monitoring of thyroid function, fasting plasma glucose and insulin level is strongly recommended regardless of growth hormone therapy.

\section{Neurocognition and Behavior}

Decreased intellectual functioning was among the four original defining characteristics of PWS [1]. Subsequent studies document a typical neurobehavioral profile that includes altered intellectual functioning and centrally driven maladaptive behaviors, including the hallmark hyperphagia that exists in the context of a more extensive food related behavioral constellation, an age related emotional and behavioral profile, altered sensory processing, social deficits and for many a predictable psychiatric profile [47-51].

\section{Intellectual Functioning}

Following the original description, early studies of intellectual development documented a wide range of intellectual abilities, although most affected individuals tested in the borderline to mildly slow IQ ranges. As more sensitive genetic testing has become available, the population of individuals with PWS has become more clearly defined. Table 3 highlights studies of individuals with PWS who had genetic confirmation of their diagnosis, and who received age appropriate and properly administered cognitive testing, supplemented with measures of adaptive functioning.

The Israeli data are notable for the number of individuals testing in a normal range, and represents a distribution of IQ scores that is quite different from the remaining four studies. The reasons for this are unclear. Setting aside the Israeli data and averaging across the remaining studies, all with approximately the same number of participants, Full Scale IQ ranges are as follows: $\geq 70$ in 21\%; mild cognitive impairment in $47 \%$; moderate cognitive impairment in $32 \%$ and severe to profound cognitive impairment in $2 \%$. An earlier report by Curf and Fryns [56] reported a greater proportion of subjects both in the $>70$ and in the mildly impaired range, however their population included many subjects for whom no genetic testing was available and thus may have included individuals who did not have PWS.

Separate from the overall range of functioning among an affected population is the question of subtype differences in intellectual functioning. Such differences may be relevant in understanding the role of various genes in the overall clinical features and phenotype of this disorder. While most studies have not found significant subtype differences in overall IQ scores, at least 2 studies have reported a greater number of UPD subjects with normal IQ scores when compared to those with deletion [57-59]. Indeed Torrado et al reported that $61.5 \%$ of those with UPD had a Full scale IQ > 70, while only $10.5 \%$ of the subjects with deletion scored in that range. However, the mean age of Torrado's subject population was 4.09 years (range 12 days-17 years), so that the significance and overall stability of the obtained IQ scores is open to question. Statistically significant subtype differences have been reported for overall Verbal vs. Performance IQ scores with at least 2 studies reporting that those with UPD have higher verbal IQ scores and those with a deletion subtype have higher performance IQ scores [49,54], although more recently Copet et al [54] found that only the greater performance IQ of the deletion group vs a disomy group was statistically significant. Keep in mind that even when subtype scores are statistically significant, in no case have those differences ever reached the level of $1 \mathrm{SD}$ for the test in question. Thus, whether these statistical differences are reflected as clinically relevant functional differences between subtypes is a question that must be raised.

Table 3 Intelligence Quotient (IQ)

\begin{tabular}{|c|c|c|c|c|c|c|c|}
\hline \multirow[b]{3}{*}{ Investigator } & \multirow[b]{3}{*}{ Year } & \multirow[b]{3}{*}{ Number enrolled } & \multirow[b]{3}{*}{ Mean Age* } & \multicolumn{4}{|l|}{ Intelligence Quotient } \\
\hline & & & & \multicolumn{4}{|c|}{ Degree of Mental Retardation (\%) } \\
\hline & & & & Normal -Borderline & Mild & Moderate & Severe \\
\hline Einfeld $^{\mathrm{a}}[47]$ & 1999 & 46 & 17.7 & 21.6 & 64.9 & 13.5 & 0 \\
\hline Gross-Tsur ${ }^{\mathrm{b}}[51]$ & 2001 & 18 & 14.3 & 73 & 27 & 0 & 0 \\
\hline Deschee-Maeker [52] & 2002 & 55 & 14.1 & 25.4 & 27.3 & 40 & 7.3 \\
\hline Whittington [53] & 2004 & 55 & 21.0 & 31 & 41.8 & 27.2 & 0 \\
\hline Copet [54] & 2010 & 85 & 24.2 & 7 & 54 & 39 & 0 \\
\hline Roof [55] & 2000 & 47 & 23.2 & 24 & 38 & 30 & 8 \\
\hline
\end{tabular}

a. Only $1 / 2$ of subjects genetically confirmed, most IQ's from records

b. Did not give a measure of adaptive functioning

${ }^{*}$ Age in Years 
In addition to mild cognitive deficits which are seen in most individuals with PWS, the overall cognitive profile at all ages includes cognitive rigidity, attentional deficits, problems with short term memory, auditory processing, sequential processing, arithmetic and social cognition. Relative strengths include long term memory, visual spatial performance, simultaneous processing, unusual abilities with jigsaw puzzles, particularly in the deletion subtype and for some reading decoding (devoid of comprehension).

\section{Neuro-behavioral Profile}

While there are a number of clinical descriptions of a typical behavior profile among those with PWS, from the earliest efforts behavioral studies have primarily focused on describing and quantifying the development of problem behaviors and psychiatric difficulties. Despite calls to include investigations of strength and adaptive behaviors [60], these remain a rare study focus. Moreover many studies include such a wide age range, often including infants through late adulthood measured at a single point in time. Parceling out developmental aspects of the behavior profile requires a critical combination of clinical and empirical evidence. Nonetheless studies across time, taken together, yield a general behavior picture that is remarkably consistent across affected individuals, despite variation in severity and intensity across individuals and within the same individual across time. Foremost among these behaviors is the hyperphagia and associated food related behavior constellation. In addition, most clinical and empirical studies document the commonality of hoarding; cognitive rigidity along with the need for sameness, temper outbursts and emotional lability, repetitive and perseverative behaviors and skin-picking.

Hyperphagia remains the cardinal defining feature of PWS. Nonetheless, the hyperphagia is only one aspect of a larger food-related behavior constellation that included preoccupations surrounding food; food seeking/foraging; sneaking, hiding and hoarding food; eating unusual food-related items (sticks of butter, used cooking grease, decaying food, garbage), food flavored items, such as shampoos and for many, manipulative and sometimes illegal behaviors designed to acquire food. While hyperphagia is found in other genetic syndromes (e.g. WAGR syndrome, Bardet-Biedel syndrome), the development of the hyperphagia and eating patterns associated with PWS, distinguish the hyperphagia associated with PWS from other disorders. Primary among these is the relatively late age of emergence, the rapid escalation and intensification of the hyperphagia following several years of poor to relatively normal eating, often accompanied early on by failure to thrive. Additional distinguishing characteristics include the duration of eating, amount of food eaten and a delayed to absent deceleration of eating, leading to gorging when both physiologic satiation and volume induced discomfort should preclude additional intake.

In the daily run of life, this is reflected as constant talking about food and unrelenting requests and demands of parents and other caregivers for food, that when denied often precipitate a tantrum. This frequently happens at the grocery or while shopping in other stores that may also have food or candy aisles and at restaurants. The denial-related tantrums can be of such a nature that parents give in as a method of avoiding the behavior, thus creating a pattern that escalates in severity and intensity over time. In addition affected individuals display a constant preoccupation with food leading to extraordinary vigilance for detecting food anywhere in the environment often resulting in stealing other's lunches at school or work, food from teacher's desks or caregiver's purses, stealing food at home or in shopping areas, begging others for food, foraging in garbage cans, entering another's home in search of food and manipulating others to obtain food. It is a rare parent who has not received a call from the school or vocational site indicating that the affected individual has been obtaining extra food by convincing caregivers that parents are ill or haven't had time to feed them, often for an extended period of time.

The etiology of the hyperphagia remains elusive. Long attributed to a hypothalamically mediated failure of satiety control $[61,62]$, current studies suggest a far more complex etiology than previously hypothesized, including, for many a theoretical reorientation that views the hyperphagia as reflecting a starvation syndrome rather than an obesity syndrome. From this vantage point, the obesity associated with PWS is seen as resulting from a physiologic signaling defect indicating that the body is in a constant state of starvation similar to that of malnourished infants, thus leading to the constant drive to obtain food.

To date there is no effective pharmacologic intervention. Management is environmental and behavioral, requiring restricted access to food in all environments, locks on cabinets and refrigerators, constant supervision, as well as measures to prevent obesity which include calorie restrictive diets, consistently scheduled meals and snacks and regularly scheduled physical activity. While simple in concept, the number of environments encountered in any given day, along with the cooperation needed from the individuals in those environments presents challenges that may be insurmountable for some families. Accounts from both parents and individuals with PWS support that strict limit setting with regard to foraging and food access is associated with reduced anxiety and a sense of safety [63]. 


\section{Behavioral Disturbances}

Separate from the food related behavioral issues, multiple studies document that affected individuals are more prone to behavioral disturbances including hoarding; inflexibility of thinking and behavior; repetitive and perseverative behaviors; the need for sameness; tantrums and emotional lability; and skin picking [62]. Furthermore, the overall rate, severity and chronicity of these disturbances are frequently more intense than those associated with comparable genetic disorders or cognitive impairments or other obese groups $[43,64,65]$. Like the hyperphagia, the behavioral patterns appear to evolve over time with predictable epochs. Most authors agree that, on the whole, infants and young toddlers with PWS are affectionate, placid and generally cheerful, largely compliant and usually cooperative. However as the hyperphagia emerges, a separate and distinctly negative behavioral shift is also observed including an emergence and escalation of both food and non food related tantrums, a shorter tolerance for frustration combined with an overreaction to frustration; repetitive and ritualistic behavior as well as becoming " stuck " or perseverating on issues both in thought and speech; and other behavior problems including increasing oppositional tendencies, a lessened ability to "go with the flow " along with a drive for sameness and "increasing stubbornness and rigidity ". Comparison studies indicate that typically developing children and other children with mental retardation also exhibit the emergence of such behaviors, but they occur only transiently, that is, the problem appears and then subsides. However the emergence of such behaviors in those with PWS not only is persistent, but appears to escalate with age, increasing in severity and intensity, independent of intellectual, language or motor abilities [66,67].

Chronic behavior disturbances, including emotional lability accompanied by unbridled displays of temper; repetitive, ritualistic and compulsive like behaviors and hoarding become particularly prevalent in adolescence and persist well into adulthood, distinguishing these individuals from both younger children and older individuals with PWS, as well as from typical adolescents. In addition there has recently been an increasing recognition of accompanying social cognition and social interaction deficits among affected individuals, including an inability to read facial expressions of emotion and difficulty interpreting visually presented social information, such as those inherent in any social interaction $[68,69]$. Indeed several authors sum up the behavioral profile of those with PWS as " egocentric " and who argue, lie, manipulate and confabulate to change rules, obtain their wishes or justify behavior. Their social judgement is poor, even considering their intellectual ability; and interpretations of visually presented social information is on a level with children who have pervasive developmental disorder [62]. Although some behavioral modulation is often seen in later ages, nonetheless problematic behaviors still exceed those seen in other comparison groups.

The expression of this behavioral phenotype does appear to depend, at least to some degree, on genetic subtype, with hoarding and overt behavioral expressions of frustration, anger and aggression more common among those with a deletion, as is a greater likelihood of modulation in middle adulthood. Internalizing and autistic spectrum behaviors are more common among those with UPD, and appear to be unremitting with little age related modulation [70,71].

Sensory Issues in the form of an altered sensitivity to pain, failure to exhibit fevers when expected and high rates of skin picking and gouging other body areas are extremely problematic among this group of individuals. While little research has been done around the issues of pain and lack of fever when expected, nonetheless blunted pain sensitivity and lack of appropriate fever response and the inherent dangers these present are clinically well documented. In this same spectrum, skin picking and other similar self injurious behavior occurs with increased prevalence in PWS when compared to a general intellectually impaired population $[67,72]$. When looking specifically at a population of those with PWS, skin picking is ubiquitous and when quantified, is as prevalent and problematic and in some studies even more so than hyperphagia [47]. It is the source of significant behavior and medical concerns and management challenges. Management is directed towards minimizing both the occurrence and impact of the behavior. To this end, a recent survey of 67 affected children and adolescents documented skin picking in $96 \%$ of respondents, which were directly associated with measures of anxiety, inattention, oppositional behaviors, function and quality of life [73]. Thus separate from medical management, behavior management must be focused on decreasing anxiety and boredom while eliminating opportunities for picking.

A number of case series across time have alluded to a small subset of individuals for whom seizures were problematic; however, it was generally thought that these represented incidental findings rather than a risk associated with PWS. A recent report by Fan et al [74] documented seizure activity in 10 of 56 subjects between the ages of 1-37 years, with suspicion in yet another 6 subjects. Among the ten subjects with documented seizure, one youngster's seizure disorder was attributed to sequelae of a grade II intraventricular hemorrhage associated with an early pre-term birth. Among the other nine cases, eight occurred in those with a deletion subtype and the other in a subject 
whose etiology was a presumed imprinting center defect; none were found among those with a disomy. After reviewing prior studies in which seizures were reported, the authors conclude that the overall prevalence of seizures in PWS is $16-17 \%$. Further they suggest that among those with a deletion, the risk for seizure in a PWS population is three to four fold times greater than that expected in a general pediatric population.

\section{Psychiatric Illness}

For many, this wide ranging problematic, behavioral profile can become sufficiently impairing that hospitalization is needed, while for others it evolves into frank psychiatric difficulties. In fact, Cassidy found behavioral concerns to be the most frequent cause of hospitalization [75]. By late adolescence $15-17 \%$ will evidence a diagnosable mood disorder [76]. This appears to be especially true for those with UPD. Separate from a categorical psychiatric diagnosis, studies consistently document that the level of behavioral and thought psychopathology, such as delusions, paranoid ideation, common in adolescents and adults with PWS exceeds that of others with an intellectual disability of other origins or of a typical population [65,67], and is the primary source of residential and vocational failure and family stress among affected adolescents and adults. While pharmacologic intervention can be helpful and in the case of psychosis is mandatory, environmental restructuring and positive behavior support programs are even more critical for facilitating recovery and preventing further difficulties.

The proliferation of less invasive and more available brain imaging techniques during the past decade offers the possibility of new insights into the central origin of the behavioral picture associated with PWS. Mantoulan [77] compared MRI and PET scans in PWS and nonPWS individuals. MRI images did not show evidence of anatomic abnormalities. However the PET scans showed hypoperfused brain regions, particularly in the anterior cingulum and superior temporal regions. The authors went on to correlate regional cerebral blood flow (rCBF) in the hypoperfused regions with results from the Child Behavior Check list (CBCL) and identified significant correlations, which suggested that the functional consequences of these perfusion abnormalities in specific brain regions might help to explain the social and behavioral issues observed in PWS. Similarly, a number of studies looking at brain processing of food related concerns have yielded mixed findings [78-80]. Functional findings must be considered tentative as the technology is sufficiently challenging that few affected individuals can tolerate the technology nor cooperate with the necessary tasks. Nonetheless, as the technology evolves, the possibility for future studies holds great promise.

\section{Sleep Disturbance}

\section{General Sleep Disturbances}

Sleep disturbance is frequent in all patients with PraderWilli syndrome independent of age and weight. PWS patients with normal weight have been shown to have multiple sleep disturbances including daytime sleepiness, disrupted sleep organization, prolonged nocturnal sleep and sleep disordered breathing (SDB). In infants, SDB consists primarily of central apneas and absent, reduced or delayed ventilatory responses and arousal to hypoxia and hypercapnia [81-84]. Adult individuals with PWSrelated morbid obesity may have the preceding sleep disturbances as well as an obesity-hypoventilation syndrome and obstructive sleep apnea.

\section{Clinical Features}

Abnormal sleep-wake organization, daytime sleepiness and sleep disordered breathing are the most common sleep related complaints. Irregular REM cycle and sleep disordered breathing appear as early as during infancy [85-87].

\section{Sleep wake organization}

Early surveys of sleep in PWS reported long nocturnal sleep (> 8 hours) as a common finding [88]. Early morning awakenings and sleep fragmentation have also been reported [89].

The most consistent finding found in polysomnographic studies has been altered rhythm of REM sleep. Studies have shown a tendency towards shorter REM latency, increased number of REM periods and shorter intervals between REM cycles. Total percentage of REM sleep appears to be normal [90-92]. REM sleep alterations appear to be unrelated to the patient genotype [93].

\section{Excessive daytime sleepiness}

Excessive daytime sleepiness (EDS) is an almost universal characteristic of individuals with PWS $[88,89,94]$. Clarke et al [88] reported EDS in more than 90\% of their surveyed patients. Those patients who reported EDS were more likely to exhibit temper tantrums during the day.

Early studies, using daytime polysomnographic recordings, confirmed the presence of pathologic sleepiness in $>95 \%$ of the patients studied [95]. Later studies employed the multiple sleep latency test (MSLT). This test, also called a " nap test " is used to measure the time elapsed to sleep onset. It consists of 4 or 5 nap opportunities during the day. The MSLT is the gold standard to quantify sleepiness and diagnose disorders of excessive sleepiness. Studies with MSLT in individuals with PWS have shown abnormally short sleep latencies and frequent sleep onset REM periods 
(SOREMPs) $[90,92,96]$. Daytime sleepiness, as measured by MSLT, appears to be independent of the degree of sleep related breathing disorders [90,92,96-98], additionally suggesting that daytime sleepiness reflects a central, possibly hypothalamic hypoarousal.

EDS and the atypical REM sleep findings bear resemblance to features of narcolepsy. Indeed, preliminary evidence in a small number of patients showed that hypocretin deficiency, a characteristic finding in narcolepsy, was also found in individuals with PWS who were severely sleepy [99]. However, in a postmortem study, there was no significant difference in the number of hypothalamic hypocretin containing neurons between patients with PWS and age matched controls [100].

Several preliminary studies have suggested a link between EDS and disruptive behavior in PWS. Hertz et al [101] reported a significant correlation between daytime sleepiness and disruptive behavior as measured by care taker's ranking. Similarly, Richdale [89] reported increased behavioral disturbance in children and adolescents with PWS who also reported EDS. Finally, in Clarke et al's [88] survey, adult patients who reported EDS were more likely to exhibit temper tantrums during the day.

In contrast, Maas et al [94], reported no significant correlation between sleep disturbance and behavioral disturbance in a group of adults with PWS.

\section{Sleep Disordered Breathing (SDB)}

Infants with Prader-Willi syndrome, as young as 4 months old, already demonstrate evidence of sleep disordered breathing. The most frequent type of SDB in infants with PWS are central apneas and periodic breathing [85,86]. Hypotonia and central control abnormalities likely play an important role. As obesity develops, around age 2 years, sleep apnea of the obstructive type becomes more common. Obstructive sleep apnea in both children and adults is directly associated with the degree of obesity and is inversely associated with age [97]. Oxygen desaturation is commonly seen even when the Apnea-hypopnea index (AHI) is only mildly elevated. The degree of sleep related oxygen desaturation may be severe, especially during REM sleep related hypotonia. Its severity is significantly increased with greater body mass index (91).

\section{Management of sleep disorders}

A sleep evaluation of all patients with Prader-Willi syndrome should be routinely considered because of the high prevalence of sleep disturbances. Patients who are habitual snorers and/or sleepy during the day may require a polysomnogram to rule out sleep disordered breathing.
In recent years, as more patients are treated with growth hormone $(\mathrm{GH})$, there has been a growing concern over the potentially adverse effects on sleep related breathing. GH may exacerbate OSA in PWS, especially in the presence of other respiratory complications [87]. Review of the death records from the French database of patients with PWS showed an association with respiratory tract infections in both $\mathrm{GH}$ and non $\mathrm{GH}$ treated patients, highlighting the need for added vigilance during these periods. In patients who were receiving $\mathrm{GH}$ treatment the concern for an adverse outcome of SDB and respiratory tract infection is particularly salient during the first nine months of treatment, more so among males [102]. Therefore, an overnight sleep study is recommended before $\mathrm{GH}$ therapy is instituted to rule out sleep disordered breathing.

The gold standard for the treatment of sleep apnea in adults is Continuous Positive Airways Pressure (CPAP) or BiPAP. In children adenoidectomy, tonsillectomy or adenotonsillectomy is often first line of treatment. Supplemental oxygen therapy may be added in the presence of obesity hypoventilation syndrome. The management of other sleep disturbances may include implementation of adequate sleep hygiene, sleep wake schedule regulation and even circadian rhythm modification.

In patients who present with excessive daytime sleepiness, a Multiple Sleep Latency Test (MSLT), is also indicated. Once diagnosed, daytime sleepiness can be managed pharmacologically or with behavioral intervention. The pharmacological management of daytime sleepiness has been controversial because of the potential side effects of stimulant medication. Additional research is needed to assess the effects of stimulant medication on daytime alertness, disruptive behavior and the general well being of the sleepy patient with PWS. Behavioral management of EDS focuses on improving nighttime sleep and scheduling daytime naps when needed.

\section{Gastrointestinal Issues}

Abnormal surges in ghrelin may precede the characteristic hyperphagia seen in PWS. Whether this causes or is the result of the lack of satiety in PWS is not clear. Left unchecked, lack of appetite control can lead to morbid obesity. Low calorie and well balanced diets with rigorous supervision and restriction of food access combined with regularly scheduled meals and activities are recommended [15]. Reduced energy requirements have been reported for children with PWS as compared to healthy, age matched controls [103-105]. Those initiating growth hormone replacement therapy may require increased caloric load during the initial muscle building phase, but once lean mass accretion has stabilized, a reduced caloric limit may again be needed. 
Poor oromotor control, muscle hypotonia and voracious eating with a limited time for mastication of food may lead to choking episodes. Choking accounts for approximately $8 \%$ of all PWS deaths. Binge eating has been seen in both obese and lean individuals with PWS. Acute gastric distention with necrosis and death has been reported with and without binging behavior. While acute gastric distention is frequently accompanied by vomiting in the general population, individuals with PWS have a decreased ability to vomit and may be missed due to lack of this important finding. These issues may be further complicated by their increased tolerance to pain which may be in part responsible for delays in seeking medical attention related to these episodes.

\section{Musculoskeletal Issues}

The prevalence of scoliosis in PWS is high (30\% before 10 yr of age; $80 \%$ after age 10 years) [106-109]. Many patients shows progression of scoliosis with age irrespective of the use of $\mathrm{GH}$ and therefore scoliosis should no longer be considered a contraindication for $\mathrm{GH}$ treatment in children with PWS.

Most published reports of scoliosis in children with PWS have been retrospective. Recent evaluation of concerns regarding worsening of scoliosis in patients currently receiving $\mathrm{GH}$ have not been substantiated $[110,111]$. Prospective studies however are warranted. Studies by Shim et al [111] showed a high prevalence of spinal deformity, limb malalignment and foot abnormalities. This group found correlations between various musculoskeletal abnormalities, independent of obesity, but noted that obesity may conceal some of these abnormalities, especially in the early stage. At this time annual musculoskeletal evaluations are recommended for scoliosis, hip dysplasia, foot abnormalities and lower limb malalignments [112].

Slipped femoral capital epiphysis is seen with increased frequency in otherwise healthy, obese children. This has not been reported with increased frequency in children with PWS.

Early work [113] compared gait strategies in patients with PWS with those of both obese and non obese healthy patients. Adults with PWS in their study were found to walk slower, with shorter stride length, lower cadence and longer stance phases compared to non PWS controls. Range of motion at the level of the knee and ankle and plantar-flexor activity were significantly reduced. Spatio-temporal gait parameters in adults with PWS were further evaluated. Using $3 \mathrm{D}$ gait analysis in an attempt to develop rehabilitation therapies, Cimolin et al [113] found that participating adults with PWS showed cautious abnormal gait strategies characterized by longer stance duration, reduced anterior step length and lower velocity of progression. Hip flexion with a forward pelvic tilt was present throughout the gait cycle. Investigators felt that this reflected an attempt to achieve balance and stability in the face of excessive body weight.

\section{Prognosis}

While there is no cure for Prader-Willi syndrome, major strides to improve quality of life have been made since the introduction of more sensitive genetic testing modalities which has allowed early diagnosis and intervention. The early use of GH has improved final adult height, body composition and muscle strength. Obesity and the consequences of obesity continue to be major risk factors for mortality in persons with PWS, even after correction for the effect associated with intellectual disability [114].

\section{Consent}

Written informed consent was obtained from the parent/guardian of the patient for publication of the accompanying image.

\section{Author details}

${ }^{1}$ The Prader-Willi Syndrome Center at Winthrop University Hospital, 120 Mineola Blvd.-Suite 210, Mineola, N.Y. 11501, USA. ${ }^{2}$ Huntington Medical Group, PC, Sleep Disorders Center, 180 East Pulaski Rd., Huntington Station, N.Y. 11746, USA. 'Saint Louis University School of Medicine, 1465 S. Grand, St. Louis, Mo. 63104, USA.

\section{Authors' contributions}

All authors contributed to the development and writing of this manuscript and each has many years of clinical experience in the care of individuals with Prader-Willi syndrome. All authors read and approved the final manuscript.

\section{Competing interests}

The authors declare that they have no competing interests.

Received: 16 June 2011 Accepted: 18 October 2011 Published: 18 October 2011

\section{References}

1. Prader A, Labhart A, Willi H: Ein syndrome von adipositas, kleinwuchs, kryptorchismus und oligophrenie nach myotonierartigem zustand im neugeborenenalter. Schweiz Med Wochen 1956, 86:1260-1261.

2. Vogels A, Van Den Ende J, Keymolen K, Mortier G, Devriendt K, Legius E, Fryns JP: Minimum prevalence, birth incidence and cause of death for Prader-Willi syndrome in Flanders. Eur J Hum Genet 2004, 12(3):238-240.

3. Whittington JE, Holland AJ, Webb T, Butler J, Clarke D, Boer H: Population prevalence and estimated birth incidence and mortality rate for people with Prader-Willi syndrome in one UK Health region. J Med Genet 2001, 38(11):792-798.

4. Nicholls RD, Knoll JH, Butler MG, Karam S, Lalande M: Genetic imprinting suggested by maternal heterodisomy in nondeletion Prader-Willi syndrome. Nature 1989, 342:281-285.

5. Butler MG: High resolution chromosome analysis and fluorescence in situ hybridization in patient referred for Prader-Willi or Angelman syndrome. Am J Med Genet 1995, 56(4):420-422.

6. Butler MG, Bittel DC, Kibiryeva N, Talebizadeh Z, Thompson T: Behavioral differences among subjects with Prader_Willi syndrome and type I or type II deletion and maternal disomy. Pediatrics Mar 2004, 113:565-573. 
7. Glenn CC, Saitoh S, Jong MT, Filbrandt MM, Surti U, Driscoll DJ, Nicholl RD: Gene structure, DNA methylation and imprinted expression of the human SNRPN gene. Am J Hum Genet 1996, 58(2):335-346.

8. Chotai KA, Payne SJ: A rapid PCR based test for differential molecular diagnosis of Prader-Willi syndrome and Angelman syndromes. J Med Genet 1998, 35(6):472-475.

9. Glenn CC, Nicholls RD, Robinson WP, Saitoh S, Niikawa N, Schinzel A, Horsthemke B, Driscoll DJ: Modification of 15q11-q13 DNA methylation imprints in unique Angelman and Prader-Willi patients. Hum Mol Genet 1993, 2(9):1377-1382.

10. Reis A, Dittrich B, Greger V, Buiting K, Lalande M, Gillessen-Kaesbach G, Anvret $M$, Horsthemke $B$ : Imprinting mutation suggested by abnormal DNA methylation patterns in familial Angelman and Prader-Willi syndromes. Am J Hum Genet 1994, 54(5):733-40.

11. Buiting K, Saitoh S, Gross S, Dittrich B, Schwartz S, Nicholls RD, Horsthemke B: Inherited microdeletions in the Angelman and Prader-Will syndromes define an imprinting centre on human chromosome 15. Nat Genet 1995, 9(4):395-400.

12. Procter M, Chou LS, Tang W, Jama M, Mao R: Molecular diagnosis of Prader-Willi and Angelman syndroems by methylation specific melting analysis and methylation-specfic multiplex ligation-dependent probe amplification. Clin Chem 2006, 52(7):1276-1283.

13. Holm VA, Cassidy SB, Butler MG, Hanchett JM, Greenswag LR, Whitman BY, Greenberg F: Prader-Willi syndrome: consensus diagnostic criteria. Pediatrics 1993, 91(2):398-402.

14. Gunay-Aygun M, Schwartz S, Heeger S, O'Riordan MA, Cassidy SB: The changing purpose of Prader-Willi syndrome clinical diagnostic criteria and proposed revised criteria. Pediatrics 2001, 108(5):E92.

15. Goldstone AP, Holland AK, Hauffa BO, Hokken-Koelega AC, Tauber M: Recommendations for the Diagnosis and Management of Prader-Willi syndrome. J Clin Endocrinol Metabol 2008, 93:4183-97.

16. Crino A, Schiaffini R, Ciampalini P, Spera S, Beccaria L, Benzi F, Bosio L, Corrias A, gargantini L, Salvatoni A, Tonini G, Trifiro G, Livieri C: Genetic Obesity Study Group of the Italian Society of Pediatric Endocrinology and Diabetology (SIEDP), Hypogonadism and pubertal development in Prader-Willi syndrome. Eur J Pediatr 2003, 162(5):327-333.

17. Eiholzer U, I'Allemand D, Rousson V, Schlumpf M, Gasser T, Girard J, Gruters A, Simoni M: Hypothalamic and gonadal components of hypogonadism in boys with Prader-Labhart-Willi syndrome. J Clin Endocrinol Metab 2006, 9(3):892-898.

18. McCandless S: the Committee on Genetics, Health Supervision for Children With Prader-Willi Syndrome. Pediatrics 2011, 127:195-204.

19. Angulo MA, Castro-Magana M, Lamerson M, Arguello R, Accachia S, Khan A: Final adult height I children with Prader-Willi syndrome with and without human growth hormone treatment. Am J Med Genet A 2007, 143A(13):1456-61.

20. Eldar-Geva T, Hirsch HJ, Benarroch F, Rubinstein O, Gross-Tsur V: Hypogonadism in females with Prader-Willi syndrome from infancy to adulthood: variable combinations of a primary gonadal defect and hypothalamic dysfunction. Eur J Endocrinol 2010, 162(2):377-84.

21. Eiholzer U, l'Allemand D, Rousson V, Schlumpf M, Gasser T, Girard J, Grüters A, Simoni M: Hypothalamic and Gonadal Components of Hypogonadism in Boys with Prader-Labhart-Willi Syndrome. J Clin Endocrinol Metab 2006, 91:892-898.

22. Akefeldt A, Tornhage CJ, Gillberg C: A woman with Prader-Willi syndrome gives birth to a healthy baby girl. Dev Med Child Neurol 1999, 41(11):789-790.

23. Schulze A, Mogensen H, Hamborg-Petersen B, Graem N, Ostergaard JR, Brondum-Nielsen K: Fertility in Prader-Willi syndrome: a case report with Angelman syndrome in the offspring. Acta Paediatr 2001, 90(4):455-459.

24. Grossman AB: The Diagnosis and Management of Central Hypoadrenalism. J Clin Endocrinol Metab 2010, 95(11):4855-4863.

25. de Lind van Wijngaarden RF, Otten BJ, Festen DA, Joosten KF, de Jong Fh, Sweep FC, Hokken-Koelega AC: High prevalence of central adrenal insufficiency in patients with Prader-Willi syndrome. J Clin Endocrinol Metab 2008, 93(5):1649-1654.

26. Connell NA, Paterson WF, Wallace AM, Donaldson MD: Adrenal function and mortality in children and adolescents with Prader-Willi syndrome attending a single centre from 1991-2009. Clin Endocrinol (Oxf) 2010, 73(5):686-8.
27. Nyunt O, Cotterill AM, Archbold SM, Wu JY, Leong GM, Verge CF, Crock PA, Amble GR, Hofman P, Harris M: Normal Cortisol Response on Low-dose synacthen $(1 \mu \mathrm{g})$ test in children with Prader-Willi syndrome. J Clin Endocrinol Metab 2010, 95(12):E464-467E.

28. Farholt S, Sode-Carlsen R, Christiansen JS, Ostergaard JR, Hoybye C: Normal cortisol response to high dose synacthen and insulin tolerance test in children and adults with Prader-Willi syndrome. J Clin Endocrinol Metabol 2011, 96(1):E173-180

29. Holm VA, Nuget JK: 1982 Growth in the Prader-Willi syndrome. Birth Defects Orig Artic Ser 1982, 18(3B):93-100.

30. Bray GA, Dahms WT, Swerdloff RS, Fiser RH, Atkinson RL, Carrel RE: The Prader-Willi syndrome: a study of 40 patients and a review of the literature. Medicine (Baltimore) 1983, 62(2):59-80.

31. Butler MG, Meaney FJ: Standards for selected anthropometric measurements in Prader-Willi syndrome. Pediatrics 1991, 88(4):853-860.

32. Lee PDK: In Endocrine and metabolic aspects of Prader-Willi Syndrome. Edited by: Greenswag LR, Alexander RC. Management of Prader-Willi syndrome, second edition, Springer-Verlag, New York; 1995:32-60.

33. Carrel AL, Myers SE, Whitman BY, Allen DB: Benefits of long term GH therapy in Prader-Willi syndrome: A four year study. J Clin Endocrinol Metab 2002, 87(4):1581-5.

34. Haqq AM, Stadler DD, Jackson RH, Rosenfeld RG, Purnell JQ, LaFranchi SH: Effects of Growth hormone on pulmonary function, sleep quality, behavior, cognition, growth velocity, body composition and resting energy expenditure in Prader-Willi syndrome. J Clin Endocrinol Metab 2003, 88(5):2206-12.

35. Festen DA, Wevers M, Lindgren AC, Bohm B, Otten BJ, Wit JM, Duivenvoorden HJ, Hokken-Koelega AC: Mental and motor development before and after growth hormone treatment in infants and toddlers with Prader-Willi syndrome. Clin Endocrinol (Oxf) 2008, 68(6):919-25.

36. Festen DA, Wevers M, Lindgren AC, Bohm B, Otten BJ, Wit JM, Duivenvoorden HJ, Hokken-Koelega AC: Mental and motor development before and during growth hormone treatment in infants and toddlers with Prader-Willi syndrome. Clin Endocrinol (Oxf) 2008, 68:991-925.

37. Myers SE, Whitman BY, Carrel AL, Moerchen V, Bekx MT, Allen Db: Two years of growth hormone therapy in young children with Prader-Willi syndrome: physical and neurodevelopmental benefits. Am J Med Genet A 2007, 143(5):443-8

38. Carrel AL, Moerchen V, Myers SE, Bekx MT, Whitman BY, Allen DB: Growth hormone improves mobility and body composition in infants and toddlers with Prader-Willi syndrome. J Pediatr 2004, 145(6):744-749.

39. Lindgren AC, Lindberg A: Growth hormone treatment completely normalizes adult height and improves body composition in Prader-Willi syndrome: Experience from KIGS (Pfizer International Growth Database). Horm Res 2008, 70(3):182-7.

40. Mogul HR, Lee PD, Whitman BY, Zipf WB, Frey M, Myers S, Cahan M, Pinyerd B, Southren AL: Growth hormone treatment of adults with Prader-Willi syndrome and growth hormone deficiency improves lean body mass, fractional body fat and serum triiodothyronine without glucose impairment: results from the United States multicenter trial. J Clin Endocrinol Metab 2008, 93(4):1238-45.

41. Hoybye C: Five year Growth Hormone treatment in adults with PraderWilli syndrome. Acta Pediatr 2007, 96(3):410-3.

42. Sode-Carlsen R, Farholt $S$, Rabben KF, Bollerslev J, Schreiner $T$, Jurik AG, Christiansen JS, Höybye C: One year Growth hormone treatment in adults with Prader-Willi syndrome improves body composition: results from a randomized, placebo controlled study. J Clin Endocrinol Metab 2010, 95(11):4943-4950.

43. Akefeldt A, Gillberg C: Behavior and personality characteristics of children and young adults with Prader-Willi syndrome: a controlled study. J Am Acad Child and Adoles Psychiatry 1999, 38(6):761-769.

44. Gondoni LA, Vismara L, Marzullo P, Vettor R, Liuzzi A, Grugni G: Growth hormone therapy improves exercise capacity in adult patients with Prader-Willi syndrome. J Endocrinol Invest 2008, 31(9):765-72.

45. Bertella L, Mori I, Grugni G, Pignatti R, Ceriani F, Molinari E, Ceccarelli A, Sartorio A, Vettor R, Semenza C: Quality of life and psychological wellbeing in GH-treated, adult PWS patients: a longitudinal study. J Intellect Disabil Res 2007, 51(Pt 4):302-11.

46. Marzullo P, Marcassa C, Campini R, Eleuteri E, Minocci A, Sartorio A, Vettor R, ALiuzzi A, Grugni G: Conditional Cardiovascular Response to 
Growth Hormone Therapy in Adult Patients with Prader-Willi Syndrome. J Clin Endocrinol Metab 2007, 92:1364-1371.

47. Einfeld SL, Smith A, Durvasula S, Florio T, Tonge BJ: Behavior and emotional disturbances in Prader-Willi syndrome. Am J Med Genet 1999, 82(2):123-7.

48. Milner KM, Craig EE, Thompson RJ, Veltman MW, Thomas NS, Roberts S, Bellamy M, Curran SR, Sporikou CM, Bolton PF: Prader-Willi syndrome: intellectual abilities and behavioral features by genetic subtype. J Child Psychol Psychiatry 2005, 46(10):1089-1096.

49. Grugni G, Crino A, Bosio L, Corrias A, Cuttini M, De Toni T, Di Battista E, Franzese A, Gargantini L, Greggio N, lughetti L, Livieri C, Naselli A, Pagano C, Pozzan G, Ragusa L, Salvatoni A, Trifirò G, Beccaria L, Bellizzi M, Bellone J, Brunani A, Cappa M, Caselli G, Cerioni V, Delvecchio M, Giardino D, lanni F, Memo L, Pilotta A, Pomara C, Radetti G, Sacco M, Sanzari A, Sartorio A, Tonini G, Vettor R, Zaglia F, Chiumello G, Genetic Obesity Study Group of Italian Society of Pediatric Endocrinology and Diabetology (ISPED): The Italian National Survey for Prader-Willi syndrome: An Epidemiologic Study. Am J Med Genet A 2008, 146(7):861-872.

50. Cassidy SB, Driscoll DJ: Prader-Willi syndrome. Eur J of Hum Genet 2009, 17(1):3-13

51. Gross-Tsur V, Landau YE, Benarroch F, Wertman-Elad R, Shalev R: Cognition, attention and behavior in Prader-Willi syndrome. J Child Neurol 2001, 16(4):288-290.

52. Descheemaeker M, Vogels A, Govers V, Borghgraef M, Willekens D, Swillen A, Verhoeven W, Fryns JP: Prader-Willi Syndrome: new insights in the behavioral and psychiatric spectrum. J Intellect Disabil Res 2002, 46(Pt 1):41-50.

53. Whittington JE, Holland A, Webb T, Butler J, Clarke D, Boer H: Cognitive abilities and genotype in a population based sample of people with Prader-Willi syndrome. J Intellect Disabil Res 2004, 48(Pt 2):172-187.

54. Copet P, Jauregi J, Laurier V, Ehlinger V, Arnaud C, Cobo AM, Molinas C, Taber M, Thuilleaux D: Cognitive profile in a large French cohort of adults with Prader-Willi syndrome: differences between genotypes. J Intellect Disabil Res 2010, 54(3):204-215.

55. Roof E, Stone W, MacLean W, Feuer ID, Thompson T, Butler MG: Intellectual characteristics of Prader-Willi syndrome: comparison of genetic subtypes. J Intellect Disabil Res 2000, 44(Pt 1):25-30.

56. Curfs LM, Fryns JP: Prader-Willi syndrome: a review with special attention to the cognitive and behavioral profile. Birth Defects Orig Artic Ser 1992, 28(1):99-104

57. Dykens EM, Cassidy SB, King BH: Maladaptive behavior differences in Prader-Willi syndrome due to paternal deletion versus uniparental disomy. Am J Ment Retard 1999, 104(1):67-77.

58. Torrado M, Araoz V, Baialardo E, Abraldes K, Mazza C, Krochik G, Ozuna B, Leske V, Caino S, Fano V, Chertkoff L: An interdisciplinary Study. Clinicaletiologic correlation in children with Prader-Willi syndrome(PWS). Am J Med Genet A 2007, 143(5):460-468.

59. Dykens EM, Hodapp RM, Walsh K, Nash J: Adaptive and maladaptive behavior in Prader-Willi syndrome. J Am Acad Child Adolesc Psychiatry 1992, 31(6):1131-1136.

60. Holland AJ, Treasure J, Coskeran P, Dallow J, Milton N, Hillhouse E: Measurement of excessive appetite and metabolic changes in PraderWilli syndrome. Int J Obes Relat Metab Disord 1993, 17(9):527-532.

61. Goldstone A: Prader-Willi syndrome Advances in genetics, pathophysiology and treatment. Trends Endocrinol Metab 2004, 15(1):12-20.

62. Benarroch F, Hirsch HJ, Genstil L, Landau YE, Gross-Tsur V: Prader-Willi syndrome: Medical prevention and behavioral challenges. Child Adolesc Psychiatr Clin N Am 2007, 16(3):695-708.

63. Whitman B, Jackson K: Tools for Psychological and Behavioral Mangement. In Management of Prader-Willi syndrome. Volume 324.. 3 edition. Edited by: Butler MG, Lee PDK and Whitman B. NY: Springer Publishing; 2006.

64. Holland AJ, Whittington JE, Butler J, Webb T, Boer H, Clarke D: Behavioral phenotypes associated with specific genetic disorders: evidence from a population-based study of people with Prader-Willi syndrome. Psychol Med 2003, 33(1):141-153.

65. Reddy $L A$, Pfeiffer S: Behavior and emotional symptoms of children and adolescents with Prader-Willi syndrome. J Autism Dev Disord 2007, 37(5):830-839.
66. Dimitropoulos A, Feurer ID, Butler MG, Thompson T: Emergence of compulsive behavior and tantrums in children with Prader-Willi syndrome. Am J Ment Retard 2001, 106(1):39-51.

67. Kim JW, Yoo HJ, Cho SC, Hong K, Kim BN: Behavioral Characteristics of Prader-Willi syndrome in Korea: Comparison with children with mental retardation and normal controls. J Child Neurol 2005, 20(2):134-138.

68. Koenig K, Klin A, Schultz R: Deficits in social attribution ability in PraderWilli syndrome. J Autism Dev Disord 2004, 34(5):573-582.

69. Whittington J, Holland T: Recognition of emotion in facial expression by people with Prader-Willi syndrome. J Intellect Disabil Res 2011, 54(1):75-85.

70. Dykens EM, Roof E: Behavior in Prader-Willi syndrome: relationship to genetic subtypes and age. J Child Psychol Psychiatry 2008, 49(9):1001-8.

71. Hartley SL, Maclean WE, Butler MG, Zarcone J, Thompson T: Maladaptive behaviors and risk factors among genetic subtypes of Prader-Willi syndrome. Am J Med Genet 2005, 136(2):140-145.

72. Arron K, Oliver C, Moss J, Berg K: Burbidge. The prevalence and phenomenology of self injurious and aggressive behavior in genetic syndromes. J Intellect Disabil Res 2011, 55(2):109-120.

73. Morgan JR, Storch EA, Woods DA, Bodzin D, Lewin AB, Murphy TK: A Preliminary Analysis of the phenomenology of skin picking in PraderWilli syndrome. Child Psychiatry Hum Dev 2010, 41(4):448-463.

74. Fan Z, Greenwood R, Fisher A, Pendyal S, Powell CM: Characteristics and frequency of seizure disorder in 56 patients with Prader-Willi syndrome. Am J Med Genet A 2009, 149A(7):1581-1584.

75. Cassidy SB, Devi A, Mukaida C: Aging in Prader-Willi syndrome: 22 patients over age 30 years. Proc Greenwood Genet Cent 1994, 13:102-103.

76. Vogels A, De Hert M, Descheemaeker MJ, Govers V, Devriendt K, Legius E, Prinzie P, Fryns JP: Psychotic disorders in Prader-Willi syndrome. Am J Med Genet A 2004, 127A(3):238-243.

77. Mantoulan C, Payoux P, Diene G, Glattard M, Roge B, Molinas C, Sevely A, Zilbovicius $M$, Celsis $P$, Tauber M: PET scan perfusion imaging in the Prader-Willi syndrome: new insights into the psychiatric and social disturbances. J Cereb Blood Flow Metab 2011, 31(1):275-82.

78. Shapira NA, Lessing MC, He AG, James GA, Driscoll DJ, Liu Y: Satiety dysfunction in Prader-Willi syndrome demonstrated by $\mathrm{f}$ MRI. J Neurol Neurosurg Psychiatry 2005, 76(2):260-262.

79. Holsen LM, Zarcone JR, Chambers R, Butler MG, Bittel DC, Brooks WM, Thompson T, Savage CR: Genetic subtype differences in neural circuitry of food motivation in Prader-Willi syndrome. Int J Obes (Lond) 2009, 33(2):273-283.

80. Miller JL, James GA, Goldstone AP, Couch J, He G, Driscoll DJ, Liu Y: Enhanced activation of reward mediating prefrontal regions in response to food stimuli in Prader-Willi syndrome. J Neurol Neurosurg Psychiatry 2007, 78(6):615-619.

81. Arens R, Gozal D, Omlin K, Livingston FR, Liu J, Keens TG, Ward SL: Hypoxic and hypercapneic ventilatory responses in Prader-Willi syndrome. J Appl Physiol 1994, 77(5):2224-30.

82. Arens R, Gozal D, Burrell BC, Bailey SL, Bautista DB, Keens TJ, Ward SI: Arousal and cardiorespiratory responses to hypoxemia in Prader-Willi syndrome. Am J Respir Crit Care Med 1996, 153(1):283-7.

83. Livingston FR, Arens R, Bailey SL, Keen TG, Ward SL: Hypercapnic arousal responses in Prader-Willi syndrome. Chest 1995, 108(6):1627-31.

84. Menendez AA: Abnormal ventilatory responses in patients with PraderWilli syndrome. Eur J Pediatr 1999, 158(11):941-2.

85. Festen DA, Wevers M, DeWeerd AW, VandenBossche RA, Duivenvorden HJ Otten BJ, Wit JM, Hokken-Koelega AC: Psychomotor development in infants with Prader-Willi syndrome and association with sleep related breathing disorders. Pediatr Res 2007, 62:221-224.

86. Cataletto M, Hertz G, Angulo M: Sleep in Infants with Prader-Willi syndrome: analysis of sleep patterns and early identification of sleep disordered breathing. Rom J Rare Dis 2010, 1(1)

87. Miller J: Sleep Disordered breathing in Infants with Prader-Willi syndrome during the first 6 weeks of Growth hormone therapy: A pilot study. J Clin Sleep Med 2009, 5(5)

88. Clarke DJ, Water J, Corbett JA: Adults with Prader-Willi syndrome: abnormalities of sleep and behaviours. JR Soc Med 1989, 82(1):21-4.

89. Richdale AL, Cotton S, Hibbit K: sleep and behavior disturbance in PraderWilli syndrome: a questionnaire study. J Intellect Disabil Res 1999, 43(Pt 5):380-92.

90. Hertz G, Cataletto M, Feinsilver S, Angulo M: REM sleep abnormalities in Prader-Willi syndrome: A genetic link. Neurology 1993, 43(4):56. 
91. Hertz G, Cataletto M, Feinsilver S, Angulo M: Sleep and breathing patterns in patients with Prader-Willi syndrome (PWS): effect of age and gender Sleep. 1993, 16:366-71.

92. Vgontzas AN, Bixler EO, Kales A, Centurione A, Rogan PK, Mascari M, Vela Bueno A: Daytime sleepiness and REM abnormalities in Prader-Willi syndrome: evidence of generalized hyperarousal. Int J Neurosci 1996, 87(3):127-39.

93. Vgontzas AN, Kales A, Seip J, Mascari MJ, Bixler EO, Myers DC, VelaBueno AV, Rogan PK: Relationship of sleep abnormalities to patient genotype in Prader-Willi syndrome. Am J Med Genet 1996, 67(5):478-83.

94. Maas AP, Sinnema M, Didden R, Maaskant MA, Smits MG, SchranderStumpel CT, Curfs LM: Sleep disturbances and behavioural problems in adults with Prader-Willi syndrome. J Intellect Disabil Res 2010, 54(10):906-17.

95. Helbing-Zwanenberg B, Kamphuisen HA, Mourtazaev MS: The origin of excessive daytime sleepiness in the Prader-Willi syndrome. J Intellect Disabil Res 1993, 37:533-41.

96. Manni R, Politini L, Nobili L, Ferrillo F, Liveri C, Veneselli E, Bianchieri R, Martinetti M, Tartara A: Hypersomnia in the Prader-Willi syndrome: clinical-electrophysiological features and underlying factors. Clin Neurophysiol 2001, 112(5):800-805.

97. Hertz G, Cataletto M, Feinsilver S: Angulo, Developmental Trends in Sleep and breathing patterns in patients with Prader-Willi syndrome. Am J Med Genet 1995, 56:188-190.

98. Caffermann D, McEvoy ED, O'Donoghue F, Lushington K: Prader-Willi syndrome and Excessive Daytime Sleepiness. Sleep Med Rev 2008, 12(1):65-75.

99. Nevsimalova S, Vankova J, Stepanova I, Seemanova E, Mignot E, Nishino S: Hypocretin deficiency in Prader-Willi syndrome. Eur J Neuro 2005, 12(1):70-72.

100. Fronczek R, Lammers GJ, Balesar R, Unmehopa UA, Swaab DF: The number of hypothalamic hypocretin (orexin) neurons is not affected in PraderWilli syndrome. J Clin Endocrinol Metab 2005, 90(9):5466-70.

101. Hertz G, McGrath A, Cataletto M: excessive daytime sleepiness in PraderWilli syndrome: behavioral and cognitive measures. Sleep 1999, 22(Suppl 1):319.

102. Tauber M, Diene G, Molinas C, Hebert M: Review of 64 cases of death in children with Prader-Willi syndrome(PWS). Am J Med Genet A 2008, 146(7):881-7.

103. Schoeller DA, Levetsky LI, Bandini LG, Dietz WW, Walcak A: Energy expenditure and body composition in Prader-Willi syndrome. Metabolism 1988, 37:115-120.

104. Butler MG, Theodore MF, Bittel DC, Donnelly JE: Energy Expenditure and physical activity in Prader-Willi syndrome: comparison with obese subjects. AM J Med Genet 2007, 143:449-59.

105. Lindemark M, Trygg K, Giltvedt K, Kolset S: Nutrient intake of young children with Prader-Willi syndrome. Food and Nutrition Research 2010, 54:2112.

106. de Lind van Wijngaarden RF, de Klerk LW, Festen DA: Hokken-Koelega AC 2008 Scoliosis in Prader-Willi syndrome: prevalence, effects of age, gender, body mass index, lean body mass and genotype. Arch Dis Child 93:1012-1016

107. Nagai T, Obata K, Ogata T, Murakami N, Katada Y, Yoshino A, Sakazume S, Tomita Y, Sakuta R, Niikawa N: Growth hormone therapy and scoliosis in patients with Prader-Willi syndrome. Am J Med Genet A 2006, 140:1623-1627.

108. Odent T, Accadbled F, Koureas G, Cournot M, Moine A, Diene G, Molinas C, Pinto G, Tauber M, Gomes B, de Gauzy JS, Glorion C: Scoliosis in patients with Prader-Willi syndrome. Pediatrics 2008, 122:499-503.

109. Greggi T, Martikos K, Lolli F, Bakaloudia G, DiSilvestre M, Cioni A, Barbanti Brodaom G, Nagai T, Obata K, Ogata T, et al: Growth hormone therapy and scoliosis in patients with Prader-Willi syndrome. Am J Med Genet 2006, 140:1623-27.

110. Odent T, Accadbled F, Koureas G, Cournot M, Moine A, Diene G, Molinas C, Pinto G, Tauber M, Gomes B, de Gauzy JS, Glorion C: Scoliosis in patients with Prader-Willi syndrome. Pediatr 2008, 122:e 499-503.

111. Shim JS, Lee SH, Seo SW, Koo KH, Jin DK: The Musculoskeletal manifestations of Prader-Willi syndrome. J Pediatr Orthop 2010, 30(4):390-395.

112. Vismara L, Romei M, Galli M, Montesano A, Baccalaro G, et al: Clinical implications of gait analysis in the rehabilitation of adult patients with
Prader-Willi syndrome: a cross sectional comparative study. J Neuroeng Rehabil 2007, 4:14.

113. Cimolin V, Galli M, Grugni G, Vismara L, Albertini G, Rigoldi C, Capodaglio P: Gait patterns in Prader-Willi and Down syndrome patients. J Neuroeng Rehabil 2010, 7:28.

114. Einfeld SL, Kavanaugh SJ, Smith A, Evans EJ, Tonge BJ, Taffe J: Mortality in Prader-Willi syndrome. Am J Ment Retard 2006, 111(3):193-8.

doi:10.1186/1687-9856-2011-12

Cite this article as: Cataletto et al:: Prader-Willi syndrome: A primer for clinicians. International Journal of Pediatric Endocrinology 2011 2011:12.

\section{Submit your next manuscript to BioMed Central and take full advantage of:}

- Convenient online submission

- Thorough peer review

- No space constraints or color figure charges

- Immediate publication on acceptance

- Inclusion in PubMed, CAS, Scopus and Google Scholar

- Research which is freely available for redistribution 